\title{
Development Research on Visual Communication Design from the Perspective of New Media Art Design
}

\author{
Beini Xin \\ Chinese National Academy of Arts, Beijing, 100029, China
}

Keywords: Visual communication design, New media art design, Visual perception

\begin{abstract}
In the new media era, visual communication design is facing great opportunities for development. On the one hand, there is a natural correlation between new media and visual communication design; on the other hand, new media has obvious progressiveness compared with traditional visual design tools. Under the background of new media art design, the development of visual communication design presents the characteristics of multimedia presentation, interactive expression and dynamic design. This paper analyzes the development situation and trend of visual communication design in the view of new media art design to provide some references for relevant researchers.
\end{abstract}

\section{Introduction}

The development of science and technology provides an opportunity for the reform of visual communication design, constantly promoting the innovation and progress of art [1]. The geometry provided a perspective theory, making the painting more fit human visual demand. The development of pigment chemistry provided the oil painters with a great sense of hierarchy and a variety of color space [2]. The in-depth study of human anatomy provided a theoretical reference for the artistic creation of sculpture, sketch and so on. The research and development of optics laid a theoretical foundation for the generation and development of photography technology, and provided an optical principle reference for Impressionist painters to explore organizational images. Therefore, the influence of the new media on art is as follows. It is obvious that the progress of science and technology has played a positive role in the development of art. Visual communication design can also be called art design. It is a kind of active behavior based on the dissemination of specific information, usually in the form of commercial advertising, painting and other forms of public view. The history of visual communication design industry has a long history and occupies an important position in the history of human civilization. Today, the unprecedented development of the market economy provides more opportunities for visual communication designers. The digitalized virtual world can break through the limitation of traditional vision and bring art creation to the new creative thinking field that transcends time, space and image experience. The goal of visual communication design is to make full use of all kinds of visual symbols to convey specific information to the audience. The new media has changed the vision of the visual communication design field, and contributed to the emergence of many new information transmission methods. The interactivity of the new media is full of the possibility and the wider creative space for the design of visual communication. The new media art not only breaks through the traditional human visual design means, but also improves the aesthetic value of the traditional visual design.

\section{Relationship between New Media Art Design and Visual Communication Design}

\subsection{Similarities}

As a new media art design developed with the development of media technology, its theoretical and aesthetic categories inherit some traditional theories of visual communication design. The 
theoretical system of traditional visual communication design can still serve as the theoretical basis of digital media art design [3]. They all must meet the basic requirements of the functionality. The aesthetic basis of aesthetic theory is the same. The theory of design and the law of graphic creativity are similar. The content of design and performance is basically common. In the process of digital media design, it meets functions and aesthetic needs, accords with aesthetics and design rules, and utilizes the characteristics of digital media, such as sound, light, electricity and human-machine interaction, to achieve the purpose of disseminating information more effectively. We can think that the connotation and characteristics of the new media art design are the further enrichment of the visual communication art design. The media refers to the form of the new media that is extended under the system supported by new technology. The new media and the traditional media have different forms of expression. Many new media are very new, such as the mobile phone terminal platform multimedia optical disc Internet technology interactive touch new media and so on. In all the design industries, graphic design in visual communication design is most susceptible to the influence of digital media art. It has no strong theoretical structure, so it tends to pragmatism. Digital devices and software make use of the convenience of modern technology to maximize the uncertainty of the designer's transformation of the mind. These are the digital equipment and software convenient function, shorten the design and creative modifications and difficulty, the designer's inspiration to get the maximum.

\subsection{Differences}

The design of new media art is a product of the times, which has advanced age, more abundant form and more scientific content [4]. The traditional design theory system in new media design also needs innovation, must according to the form of information dissemination, the media and the dissemination of the composite and discipline comprehensive technology, digital features to improve this emerging discipline. In the process of design, the new media not only makes the design process change, but also has a profound influence on the design style and the way of thinking. The layout and a full range of interactive activities are required to treat time layout and visual effect in motion vision, not only consider the static visual effect, but also a variety of appearance after the idea of interactive visual elements and the audience may appear, through targeted design to avoid interference or picture message is not beautiful. Video and animation will be used as common elements, together with text and graphics to form a layout, and be changed at any time to deal with the increasing segmentation and preferences of audiences to meet people's aesthetic needs, and to accomplish the visual communication of information more effectively. Visual communication is designed for information transmission, but it cannot be separated from the media. The relationship between media and visual communication design is interactive. The media not only embodies the design but also brings limitations to the design. The design is not only subject to the media, but also the power generated by the new media. In the new media era, designers can more easily inject innovative power into product programs, so that products can embody the humanistic concern and give different audiences the experience of using products. At this stage, almost all the creative work of visual communication design needs the power of new media tools.

\section{Development Situation of Visual Communication Design under the Background of New Media Art Design}

\subsection{Multi-sense Visual Communication Design}

In the process of communication, traditional media have different forms of expression and play different roles. The emergence of new technology and new media and the transmission of personality have changed people's access to visual information and aesthetic needs. From the content to the media to the audience, various problems need new media visual design to face and solve. New media integrates many media elements, such as text, voice, image, image, color, music, game and so on. It has many kinds of media technology support, and can use multiple design elements synthetically, and 
overcome the obstacles between traditional media. It presents a variety of visual design methods, and the design means and methods of communication can be leapfrog. Is the human sensory stimulation of sensory organs, mainly eye ear nose, tongue and body features, namely human vision, hearing, smell, taste and touch; visual perception, is the object's size, brightness, color, movement, all kinds of information are of great significance to the survival of the organism, at least $80 \%$ of information by vision, vision is the most important feeling. Therefore, the information transmission mode of human society has always focused on the visual transmission, that is, the development of visual communication design. At present, the computer is one of the most visual multimedia equipment designers, the combination of computer technology and the theory of visual communication design for organic integration, the birth of a new vision of digital technology and computer technology framework based on the means of communication design, new design tools can give the audience a strong visual effect, rich. Through the large-scale use of computer technology in visual communication design, staff have created various forms of artistic techniques, greatly promoting the progress of the industry.

\subsection{Interactive Visual Communication Design}

In the era of new media development, visual communication design should change the way of passing duck information in the past, and turn to interactive information transmission. The interactive design of information is to make the information transfer easy and effective, let the audience accept the information at the same time have a pleasant experience. The design of this information transmission needs to be based on the understanding of the psychological behavior and characteristics of the information audience. With the development of network and new technology, there are more and more new products and interactive ways, and people are paying more and more attention to the experience of interaction. Visual communication design should also adjust the way of information transfer in time to meet the needs of the audience. For new media, the concept of human-machine interaction design enables users to easily use information when they receive information, and can quickly accomplish the transmission of a certain message. The media elements of new media are interactive, interactive design is consistent with humanization and personalized design, which means that the audience's acceptance of information is no longer a passive receiver. The role of audiences is changing, and they begin to accept the content displayed in visual design voluntarily. The new media is built on the Internet, and most of the operation design will take the mobile platform as a priority. But the most important thing is to use the interface design of smart phone devices. Because the mobile phone screen, web designers in the design of web pages will likely be simplified picture elements, including links as skills with images, which are to be designed for mobile phone group mode, thereby reducing a complex picture the presence of components. This kind of participation can not only improve the efficiency of information transmission but also enhance the memory of the audience, and make the interactive process complete.

\subsection{Dynamic Visual Communication Design}

When the audience is fatigued with the static visual information which is often seen, dynamic visual information appears in time, and it adds new vitality to people's vision. The development of visual communication design from static design to dynamic design no longer has any technical problems, it will also become a new trend of development. More dynamic visual information can be attracted to the audience's eyeballs, and the amount of information transmitted will be more than static visual information. Dynamic visual information can not only transmit information effectively, but also improve the utilization of visual space. Dynamic design cannot do without the web design and digital media advertising and other fields of visual communication, but does not mean that visual communication cannot be other areas to try, for example we used life book design, packaging design, logo design, these designers are waiting to exploration and development. In the whole design process, the designer is the integrator of information, creating a brand new interpersonal relationship through virtual space, linking people with different backgrounds through links. Visitors can also communicate their information through the same channels to the organizers, from the traditional form 
of one-way transmission to two-way transmission. Dynamic images are more likely to be captured for human instincts, and initiative is more acceptable than passive action. The interactivity and connectivity of the new media art are its most distinctive features. In the process of integration of new media and traditional visual communication, it conveys the transformation from static design to dynamic design, while dynamic design is fresher to express people's needs while conveying freshness. The interactive interesting experience of new media brings vitality to visual communication, and integrates the visual communication design of interaction process, changing the invariable state of the initial presentation of the work, instead, it is a starting point to guide the audience to take the initiative to participate in it. Thus, communication and interaction have become the focus of visual designers in the creation of new media art.

\section{Development Trend of Visual Communication Design under the Background of New Media Art Design}

Both the new media art design and the visual communication design, their development cannot be separated from the development of science and technology, both have a certain correlation. The development of new media art, to a certain extent, has a profound impact on visual communication design. The high-tech, interaction and interest of new media art are inspiring the creative thinking of visual communication. This is not only about the application of their common elements in new media, such as color, graphics, fonts, but also the influence of information movement, voice and interaction on audiences. Throughout the development process of human civilization, science and art are always in the mutual promotion of development, like digital technology so to arouse the art field caused an unprecedented change less and less. New media art has been deeply rooted in the modern life, and deeply changed the form of art design, art appreciation mode and transmission mode of thinking and art, people take advantage of this new form of art has greatly enriched the content of artistic expression and artistic creation feelings, full of heart, to meet the needs of the art of living. In the future, new media art China will follow the pace of the civilian gradually popular, widespread popularity of digital devices, people to master computer technology more skilled, so that everyone may become the new media art designers and creators, the continuous development of digital technology and information network technology are constantly urge the public to participate in them, new media design art will be to people and civilians, will gradually return to public art. It should be noted that in the future, new media art and design will increasingly depend on digital image and digital technology support. Digital imaging and digital technology will become the mainstream trend of the society with the development of new media era. As the crystallization of art and modern science and technology, the art design of new media in China will become the most promising and promising popular art in the new century.

\section{Conclusions}

The new media is exerting a great influence on the modern visual communication art design. With the support of science and technology, today's visual communication design is stepping out of graphic design and moving towards the direction of multimedia presentation, interactive expression and dynamic design. Visual communication designers should actively improve their overall quality, maximize the use of new media technology, and promote the rapid development of visual communication design industry.

\section{References}

[1] Tian Yicai. New Ideas of Visual Communication Design in the Digital Era [J]. Art and Design, 2016(7): 51-53.

[2] Zhang Yang. The Educational Innovation of Visual Communication Design in New Media Era [J]. Design, 2015(24): 140-141. 
[3] Yang Zhen. New Direction of Visual Communication Design in Europe: Information Design [J]. Value Engineering, 2013(15): 213-214.

[4] Wang Lili. Educational Reform of Visual Communication Design with the Development of Mobile Digital Media [J]. Education Teaching Forum, 2017(43): 124-125. 